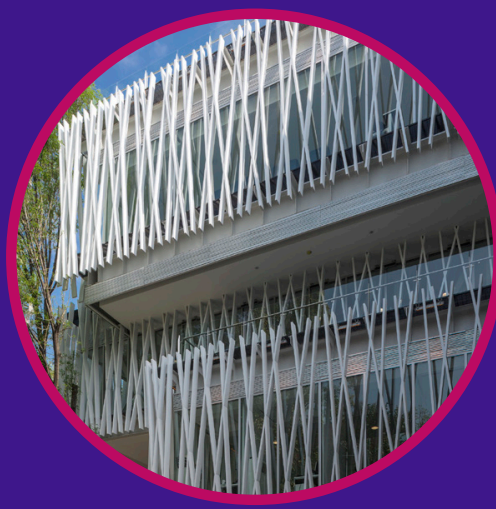

\title{
Presentación del Observatorio de Cultura Fotográfica
}

\author{
Presentation of the Photographic Culture Observatory
}

\author{
REDACCIÓN
}

Universidad Panamericana

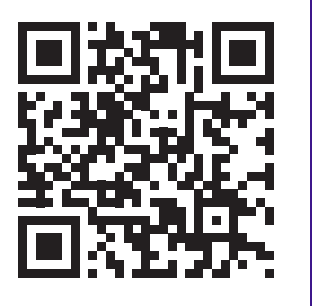

(c) (†) $\ominus$ Esta obra está bajo una licencia internacional Creative

DOI: https://doi.org/10.21555/rpc.voi1.2329

Cómo citar: Redacción de la Revista Panamericana de Comunicación. (2020). Presentación del Observatorio de Cultura Fotográfica. RPC, (1), 149-150. https://doi.org/10.21555/rpc.voi1.2329

Revista Panamericana de Comunicación, Año 2, N. 1, enero-junio 2020, pp. 149-150.

Frente a una realidad actual construida en gran parte por información visual a través de redes sociales, nació la idea de crear un Observatorio de Cultura Fotográfica (OCF) para tener un espacio de observación y análisis de fenómeno fotográfico a nivel individual y de comunidad.

El OCF, arrancó labores, el día 24 de septiembre del 2019, a iniciativa del Dr. Óscar Colorado Nates y con el apoyo de la Escuela de Comunicación de la Universidad Panamericana y sustentado por un conjunto de académicos, intelectuales y profesionales de la fotografía en México y en el mundo.

El Observatorio busca responder a un cuestionamiento central: ¿Cómo nos estamos articulando como colectivo humano a través de la fotografía? La respuesta es fundamental apra responder a esa necesidad de entender cómo influye la fotografía a la cultura y a los sistemas de pensamiento contemporáneos.
Cabe mencionar a algunos de los participantes actuales como el Maestro Juan Carlos Valdés, director de la Fototeca Nacional; reconocidos creadores fotográficos actuales como los maestros Francisco Mata Rosas, Ulises Castellanos, Nicola Lorusso o Gerardo Suter; los académicos Jacob Bañuelos (Instituto Tecnológico de Estudios Superiores de Monterrey), Edgar Gómez Cruz (University of New South Wales); José Luis Ortiz Garza y Francisco Javier Díaz Guerrero (UNAM); Manuela Paterna, Leonardo Guzmán, Margarita Mena, Yoatzin Balbuena y Francisco Mercado (Universidad Iberoamericana); Luis Beltrán (Escuela Activa de Fotografía, Querétaro) entre otros destacados investigadores.

La fotografía se está transformando con más velocidad de la que se es posible analizarla a través de papers o tesis. Somos, recordando a Deleuze, ciegos ante la hipersensibilidad del mundo; ante la veloz y compleja cantidad de información. Así, el OCF, se pre- 
senta como una propuesta metódica, sistemática y rigurosa que permita la reflexión seria y que sirva como un acicate para construir conocimiento a partir del ecosistema fotográfico reciente.

La necesidad de estudiar los fenómenos sociales desde la fotografía surge porque estamos en un momento donde las imágenes han logrado hacerle frente al ritmo de las sociedades actuales. Los medios de información más importantes, así como los medios sociales más recurridos, se encuentran regidos por el uso de imágenes como herramienta para distribuir información y dotarla de legitimidad.

\section{LOS ELEMENTOS CONSTITUTIVOS PARA EL OCF SON:}

Observatorio: Como una especie de panóptico, un núcleo desde donde se pueda detectar lo que importa ser detectado y poder observar para reflexionar no para criticar ni juzgar, sino para cuestionarse qué significa lo que ocurre y qué efectos está teniendo. Se trata de buscar una mirada dentro del fenómeno, pero extraído para poder mirar.

Cultura: Un concepto elusivo, complejo definir, siempre en constante construcción y en movimiento. Se trata de un entorno vivo pero que, para fines del OCF, hace suyas las palabras de Helen Spencer: Cultura es "una fotografía instantánea de nuestra sociedad".

Fotografía: Es el objeto de estudio del OCF. Se está haciendo más fotografía que en ninguna otra época y sigue evolucionando, por lo que es pertinente analizar y examinar este fenómeno. Verlo de manera específica, distinguir la producción y distribución desde todos sus ángulos, su circulación, la memoria y el almacenamiento.

Para el Dr. Óscar Colorado, el OCF implica el reto de tratar de comprender lo que ocurre en el momento presente, ayudados por el pasado pero siempre con una mirada puesta en el futuro. Será seguramente un camino complejo, pero se pueden distinguir convergencias y patrones dentro de este sistema caótico: "No hay sociedad que conozcamos mejor a partir del siglo XIX gracias a la fotografía ¡Cuánta información se está generando sobre nuestro propio tiempo a través de las fotografías que hacemos constantemente!" reflexiona el fundador del OCF.
Hoy en día, las cantidades de información que se producen dificultan la posibilidad de hacer ejercicios de discernimiento, análisis y crítica por el veloz flujo de producción y distribución. La otrora autoridad de la palabra escrita ha sido cedida y se complementa por medio de la aseveración que una fotografía puede otorgar.

Con este mecanismo se ahondará en los retos de la fotografía en los medios de comunicación contemporáneos, tanto los verticales y hegemónicos tradicionales impresos (periódicos, revistas) como los horizontales sociales en la esfera digital con enfoque específico en Instagram, Facebook y Twitter.

El Observatorio de Cultura Fotográfica busca tener una perspectiva basada en el análisis transversal desde la producción, emisión, distribución y recepción de los mensajes visuales portadores de perspectivas cotidianas, concretas y abundantes en la sociedad.

Esto obliga a poner en tela de juicio el actual alcance de la imagen como una fuente fidedigna de información. Es necesario por ello que se fomenten estos ejercicios de discernimiento, análisis y crítica, que logren filtrar la cantidad inmensurable de información que se produce diariamente. Se busca generar nuevas herramientas de observación y nuevas herramientas metodológicas que ayuden a observar este fenómeno tan complejo.

Ser parte del Observatorio de Cultura Fotográfica es una convocatoria abierta a toda la comunidad académica y de artistas de fotografía para participar y sumarse a este diálogo. ।

Búscanos en redes sociales como: @observafoto

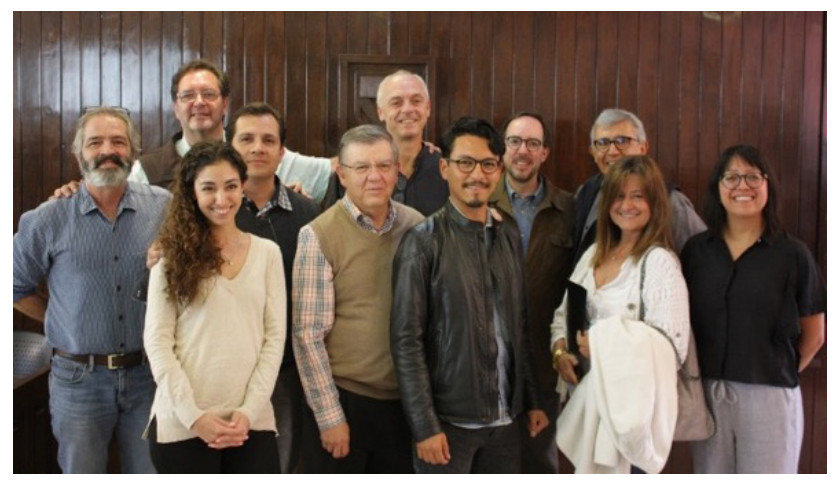

De atrás hacia adelante y de izquierda a derecha: Leo Guzmán, Nicola Lorusso, Óscar Colorado, Francisco Mata, Luis Beltrán, Francisco Mercado, José Luis Ortiz, Paco Díaz, Manuela Paterna, Yoatzin Balbuena, Margarita Mena. 